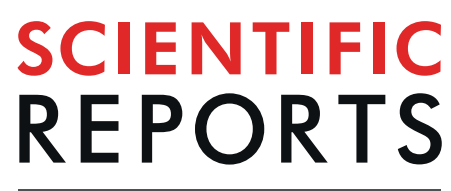

natureresearch

\title{
Delegated Regressor, A Robust Approach for Automated Anomaly Detection in the Soil Radon Time Series Data
}

\author{
Muhammad Rafique ${ }^{1 *}{ }^{*}$, Aleem Dad Khan Tareen ${ }^{1}$, Adil Aslim Mir ${ }^{2}$, \\ Malik Sajjad Ahmed Nadeem ${ }^{2}$, Khawaja M. Asim ${ }^{3,5}$ \& Kimberlee Jane Kearfott ${ }^{4}$
}

We propose a new method based on the idea of delegating regressors for predicting the soil radon gas concentration (SRGC) and anomalies in radon or any other time series data. The proposed method is compared to different traditional boosting e.g., Extreme Gradient Boosting (EGB) and simple regression methods e.g., support vector regressors with linear kernel and radial kernel in terms of accurate predictions. $R$ language has been used for the statistical analysis of radon time series (RTS) data. The results obtained show that the proposed methodology predicts SRGC more accurately when compared to different traditional boosting and regression methods. The best correlation is found between the actual and predicted radon concentration for window size of 2 i.e., two days before and after the start of seismic activities. RTS data was collected from 05 February 2017 to 16 February 2018, including 7 seismic events recorded during the study period. Findings of study show that the proposed methodology predicts the SRGC with more precision, for all the window sizes, by overlapping predicted with the actual radon time series concentrations.

During past few decades several studies have been carried out across the globe focusing on earthquake prediction based upon anomalous behavior of radon gas in atmosphere, soil and water. Many studies, since after first evidence of a correlation between radon in well water and earthquake (1966; $M=5.3)$ occurrence, reported by Ulomov and Mavashev in 1967 for the Tashkent earthquake, have recognized that anomalous behavior of radon in soil and groundwater can serve as a precursor for a forthcoming earthquake ${ }^{1}$. Sultankhodzhayev et al. in 1976 have reported the rise of the radon concentration in a spring before the Gazli earthquake (17 May $1976 ; M=7.3)^{2}$. A number of studies conducted in China reporting radon anomalies before strong earthquakes compelled scientists in the rest of the countries to carry out systematic investigation to probe possible link between radon anomalies and earthquake prediction ${ }^{3,4}$. Several studies have reported correlation between impending earthquakes with variability of radon gas in soil and ground water ${ }^{5-23}$.

Walia et al. 2005, have shown that micro-seismic events recorded along the Main Boundary Thrust (MBT) of $\mathrm{N}-\mathrm{W}$ Himalaya in the grid $\left(30-34^{\circ} \mathrm{N}, 74-78^{\circ} \mathrm{E}\right)$ have correlation with radon anomalies ${ }^{24}$. The same study revealed that $62 \%$ of micro-seismic events have correlation with the precursory nature of radon ${ }^{24}$. Their findings revealed, as reported in some other studies ${ }^{20,23}$, that radon anomalies are not only influenced by seismic events but also by meteorological parameters. Ramola et al. 2008, have reported spike-like and sharp peak anomalies in radon time series data before, during and after earthquake occurred in Garhwal Himalaya ${ }^{15}$.

Besides having a considerable number of research studies addressing radon anomalies serving for earthquake precursor based upon their experimental findings, yet there are some scientists who had produced thematic papers on radon as precursor for earthquake forecasting 25,26 .

Since anomalies in RTS data may arise due to multiple factors including seismic events, meteorological parameters, so forth. This leads to serious impediments in differentiating anomalies caused by seismic activities

${ }^{1}$ Department of Physics Chehla Campus, University of Azad Jammu and Kashmir Muzaffarbad, 13100, Azad Kashmir, Pakistan. ${ }^{2}$ Department of Computer Science and Information Technology, University of Azad Jammu and Kashmir, Muzaffarabad, 13100, Azad Kashmir, Pakistan. ${ }^{3}$ Centre for Earthquake Studies, Islamabad, Pakistan. ${ }^{4}$ University of Michigan, Department of Nuclear Engineering and Radiological Sciences, 48109-2104, Ann Arbor, MI, USA. ${ }^{5}$ GFZ German Research Center for Geosciences, Potsdam, Germany. *email: mrafique@gmail.com 
and those caused exclusively by environmental factors. Tareen et al. 2019 used same data set to identify the parameters, viz. environmental parameters, noise or seismic activity, influencing or triggering anomalies in radon time series data. Findings of that study showed that under meticulously characterized environments, on exclusion of noise contribution, seismic activity is responsible for anomalous behavior seen in current RTS data. Such situations can be handled using Machine Learning Methods (MLMs).

Machine learning has been successfully applied to many problems in the environmental sciences ${ }^{27}$. With MLMs, a model for the prediction of radon concentration can be built, taking into account various environmental parameters (e.g., barometric pressure, rainfall, and air and soil temperature). Such models can subsequently be used to identify radon anomalies triggered by seismic events. The application of artificial neural networks ${ }^{28-30}$, regression and model trees ${ }^{31-34}$ and different other methods $s^{32,35}$ have proven to be useful for extracting radon anomalies caused by seismic events.

Diagonal Linear Discriminant Analysis- DLDA ${ }^{36}, k$-Nearest Neighbors- $k \mathrm{NN}^{37}$, Support Vector Machine ${ }^{38}$ and Random Forest ${ }^{39}$ have been employed for classification and regression purposes. These methods have applications in decision support systems $\mathrm{s}^{40-42}$ and earthquake prediction studies ${ }^{33,43-45}$. Analyses of the radon data from three stations in the Krsko basin, Slovenia ${ }^{33}$, showed that model trees outperformed other regression methods. Negarestani et al., 2002, experimented layered neural network (LNN) to estimate the radon concentration in soil related to the environmental parameters that can find any functional relationship between the radon concentration and the environmental parameters ${ }^{28}$. Singh et al., 1999, observed the significant increases in radon concentration of groundwater and water level which are correlated to the seismic events which occurred in Northern India during the period of study ${ }^{46}$.

Freund and Schapire 1998, proposed the well-known AdaBoost.M1 (also known as Discrete Adaboost) algorithm ${ }^{47}$. Friedman et al..$^{48}$ worked on boosting and developed gradient boosting algorithm, which uses machine learning techniques to make weak classifiers usually decision tress and then make the final prediction, is based on the aggregate of this weak classifier. In 2000, He established connections of Adaboost.M1 algorithm to statistical concepts such as loss functions, additive modeling, and logistic regression. The step of taking the random sampling in boosting is motivated by Breiman's bagging procedure that makes the nature of boosting to be stochastic. In addition, it develops the idea of delegating classifiers in a systematic way by delegating the difficult or uncertain predictions to other, possibly more specialized classifiers. On the other hand, Ferri et al., 2004, also presented an iterated scenario involving an arbitrary number of chained classifiers ${ }^{26}$.

In this study we propose a new method based on delegating classifier ${ }^{26}$ for predicting the radon concentration and anomalies in soil radon time series data by delegating the samples to the next lower level that do not meet the desired threshold e.g., uncertain predictions. The proposed methodology has foundations regarding classification task by keeping the power of delegation in classification. For analysis purpose, RTS data was obtained for the period from 05 February 2017 to 16 February 2018 including 7 seismic activities recorded during this period. The proposed method is compared to different traditional boosting (Extreme Gradient Boosting) and simple regression methods (support vector machines with linear kernel support vector machines with radial kernel) based on how much they accurately predict the radon concentration. The extreme gradient Boosting method is the most popular and extensively used ensemble approach that has had been successfully used for the regression problems and also Support Vector Machine technique (with linear and radial kernels) which is also the most popular method for regression problems. The results obtained depicts that the proposed methodology predicts more accurately the RTM 1688-2 measured RTS data when compared to different traditional boosting and regression methods.

\section{Materials and Methods}

Location and instrumentation. Current study is performed in Muzaffarabad, a city in Pakistani territory of Kashmir. A radon station, for the continuous measurement of radon time series data, was installed in highly active seismic zone. RTM 1688-2, (SARAD RTM 1688-2, Nuclear Instruments, Germany) was installed at the fault line passing beneath the Chehla with latitude 34.39621 and longitude 73.47347. The location of radon monitoring station lies within $150 \mathrm{~km}$ of the Centre of the strongest earthquake in the region since 1900. Packer probe was placed with already digged borehole and sealed to avoid ambient air contact. Than Packer probe was connected to the RTM 1688-2, (SARAD RTM 1688-2, Nuclear Instruments, Germany), placed within a 1 meter of the soil surface.

The RTM 1688-2 measures the ${ }^{222} \mathrm{Rn}$ concentration in slow i.e., contributions from the disintegrations of both ${ }^{218} \mathrm{Po}$ and ${ }^{214} \mathrm{Po}$, and Fast modes for which only ${ }^{218} \mathrm{Po}$ decay events are counted. The RTM 1688-2 device measures humidity (0 to $100 \%)$, temperature $\left(-20\right.$ to $40^{\circ} \mathrm{C}$ ) and barometric pressure (800 to $1200 \mathrm{mbar}$ ). We have operated the instrument in slow mode for measurement of radon gas in current study. RTS data were collected in $40 \mathrm{~min}$ intervals with 36 readings per day spanning over a period of one year.

Proposed methodology. Complete simulation plan for radon anomaly detection using different machine learning methods is shown in Fig. 1.

Since radon concentration is a numeric variable, we have approached the task of predicting radon concentration from meteorological data using regression (or function approximation) methods. In order to predict the radon concentration at different periods of time before and after the seismic activity, the dataset is divided into two parts i.e. seismic and non- seismic radon data. For each window size the seismic radon data comprises of the days before and after the seismic events viz. window size of 1 means 1 day before and after the seismic event. Algorithm developed for proposed methodology is given as; 


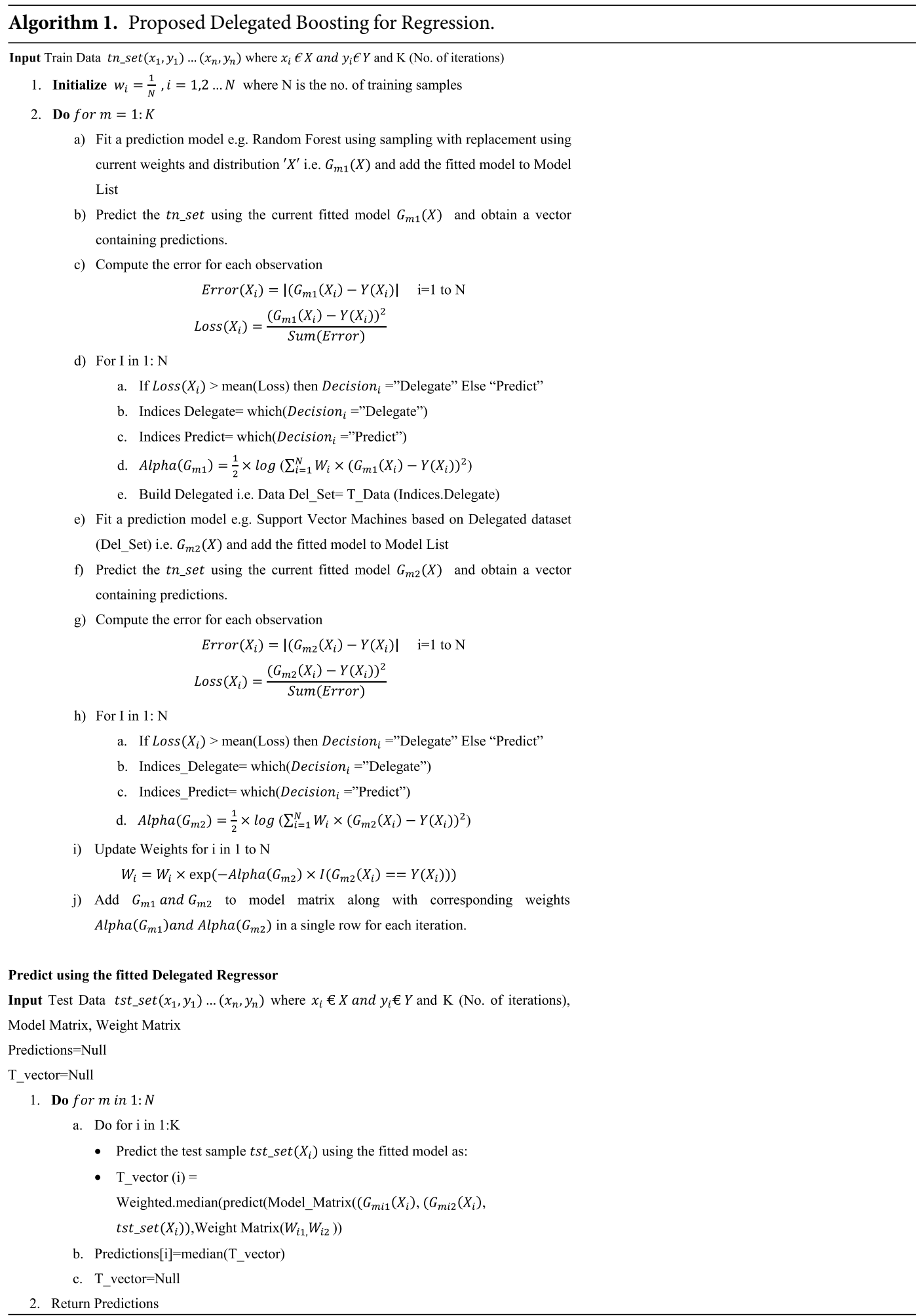

Return predictions. The total number of samples in the dataset are 13456; including 7 seismic activities. The data has been divided into two parts: seismic data, containing anomalies, and treated as test data while non-seismic, without anomalies, and is taken as training data. The number of samples in the training and test data varies with respect to window size. With the increase in window size, the number of samples in the test data starts increasing as compared to training data which decreases. On increasing the window size, i.e. days before and after the seismic activity, the sample from non-seismic training data is added to seismic data (i.e. test data).

The predictive performance of the regression methods was determined using root mean squared error (RMSE). The RMSE measures the discrepancy between measured and predicted values of radon concentration. Smaller RMSE values indicate lower incongruities. There are other metrics in order to measure the error for predictions e.g. MSE (mean squared error) which is the most simpler and commonly used metric for regression 


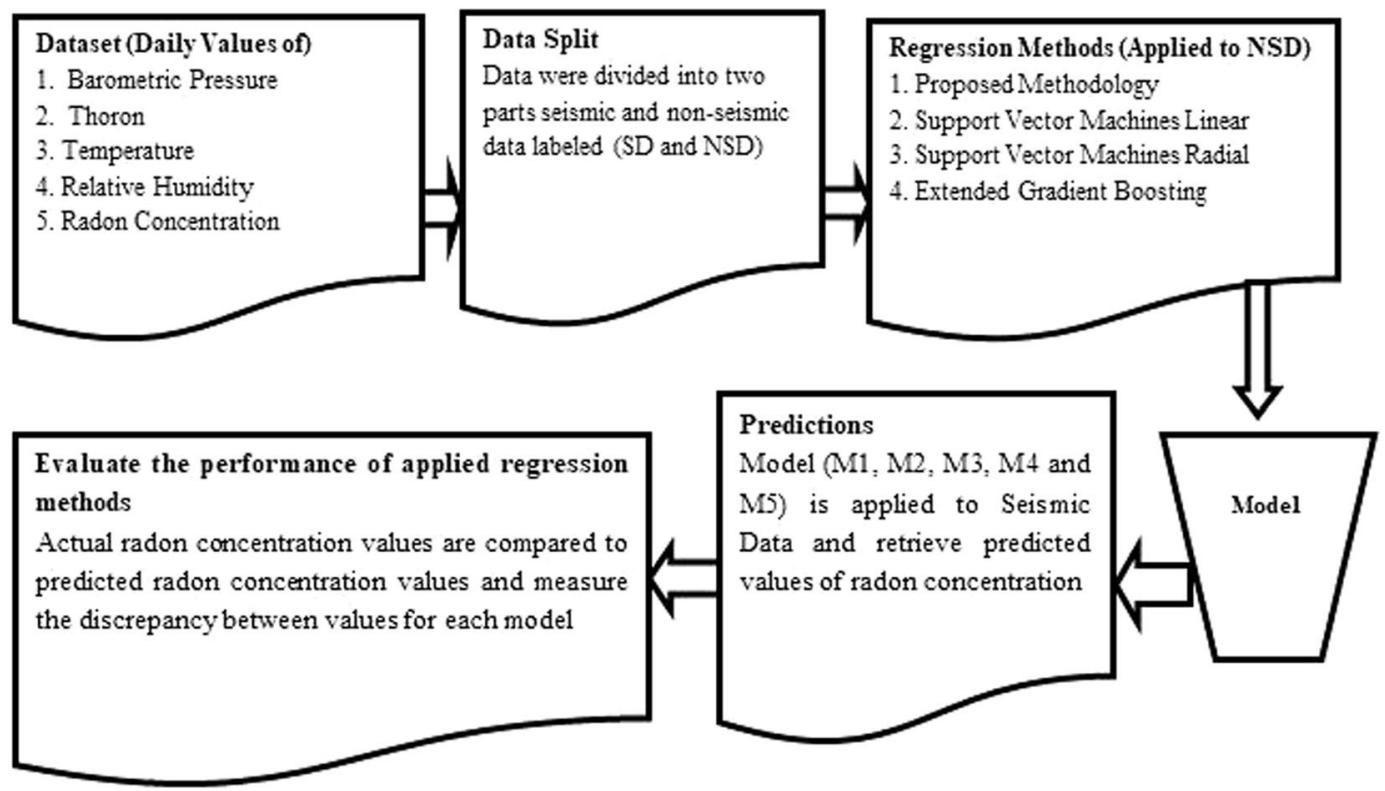

Figure 1. Simulation Plan for radon anomaly detection using different machine learning methods.

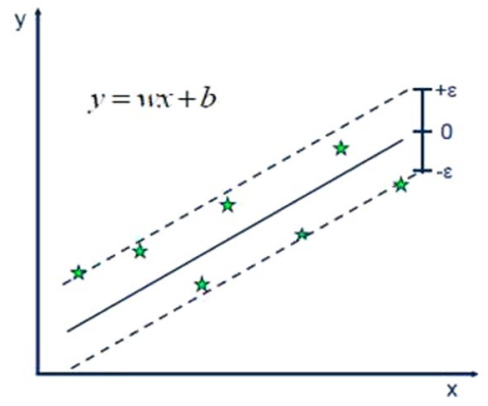

$$
\begin{aligned}
& \text { - Solution: } \\
& \min \frac{1}{2}\|n\|^{2} \\
& \text { - Constraints: } \\
& y_{i}-1 x_{i}-b \leq \varepsilon \\
& 1 x_{i}+b-y_{i} \leq \varepsilon
\end{aligned}
$$

Figure 2. Basic representation of Support Vector Machine for regression ${ }^{60}$.

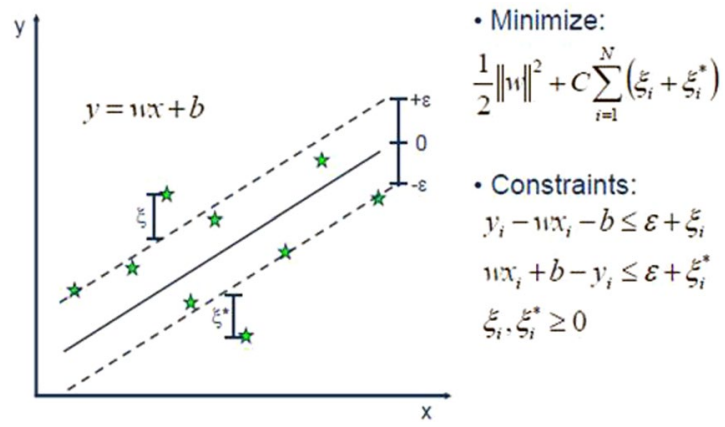

Figure 3. Support Vector Regressor with slacked variable ${ }^{60}$.

evaluation tasks but the problem in this metric is that if we make only a single prediction very bad, it makes the error even worst because of squaring the distance between actual and predicted values and skews the metric in the direction of overvaluing the computed model's badness. In order to make errors to meet the scale of targets, a square root is introduced on MSE but travelling along the RMSE gradient is same as travelling along MSE gradient but at a different flowing rate. Moreover, in the literature authors also used RMSE as a metric for estimation of error.

To test the hypothesis for the predictability of radon concentration in periods with and without seismic activities, the following procedure was applied. First, the value of the class-daily radon concentration; and the values 


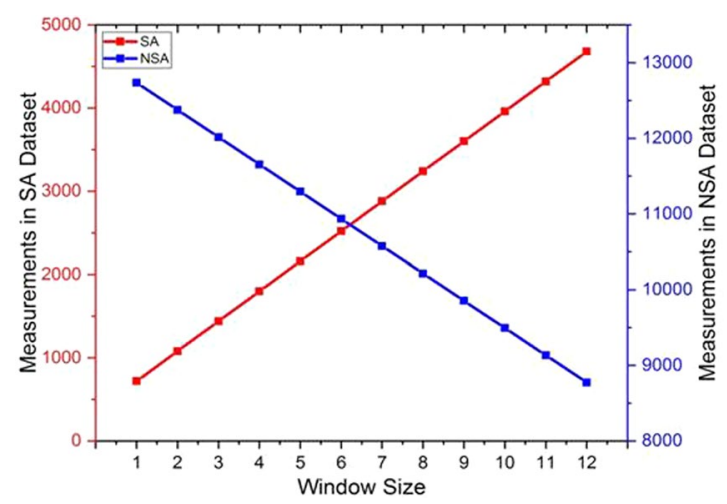

Figure 4. Number of measurements in seismic and non-seismic dataset with respect to window sizes ranging from 1 to 12 .

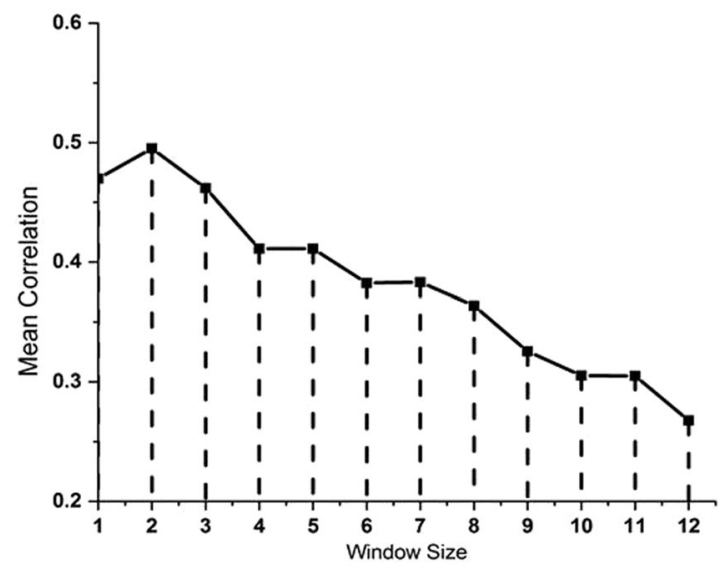

Figure 5. Mean correlation of actual and predicted radon concentration using different regression methods.

of attributes-barometric pressure, thoron, temperature and relative humidity was selected. Second, this data set was split into two parts. In the first part (labeled SA), data for the periods with seismic activity were included, i.e., periods of 12 days before and after an earthquake. Data for the remaining days were included in the second part, belonging to the seismically non-active periods (labeled non-SA). We have applied the methodology by utilizing the proposed and traditional methods, we trained the models on non-seismically active data part and obtained each respective model. Moreover, from each model we have predicted the seismically active data part and obtained the predicted radon concentration. Finally, we estimated the error regarding predicted and actual values. The performance of the model depends upon how much the actual and predicted values of radon are closed to each other.

\section{Machine Learning Prediction Methods}

Extreme gradient boosting. XGBoost (Extreme Gradient Boosting) has become one of the most popular machine learning algorithms for classification and prediction problems ${ }^{49}$. Gradient Boosting was developed as a generalization of AdaBoost by observing gradient search of AdaBoost in decision tree space against a particular $\operatorname{cost~function~}^{50}$. The innovation of Gradient Boosting39,51 was the observation that can use different cost functions, some of which were more suitable to the domain than the one that was implicitly used in AdaBoost.

Gradient Boosting was however overwhelmed by a lot of ad-hoc parameters to control the growth of the decision trees in the algorithm ${ }^{51}$. XGBoost ${ }^{52}$ was developed to put this on a more formal footing. In XGBoost the size of the tree and the magnitude of the weights are controlled by standard regularization parameters. This leads to a 'mostly' parameter-free optimization routine. In theory that is, as in practice a plethora of parameters are used, still to control the size and shape of the trees. Regularization did however proved to be very powerful and made the algorithm much more robust.

Real extreme gradient boosting is better regularized model formalization of Gradient Boosting that gives better performance to control the over-fitting problem. Therefore, it helps to reduce over fitting regarding training data. Its roots begins from the implementation of gradient boosting machines but now because of its efficiency and better performance, it is now associated to a more extensive collection of tools under the umbrella of the distributed machine learning community ${ }^{53}$. 


\begin{tabular}{|l|l|l|l|l|}
\hline $\begin{array}{l}\text { Win } \\
\text { Size }\end{array}$ & $\begin{array}{l}\text { Extreme Gradient } \\
\text { Boosting (XGBoost) }\end{array}$ & $\begin{array}{l}\text { Support Vector } \\
\text { Machine Linear } \\
\text { (SVML) }\end{array}$ & $\begin{array}{l}\text { Support Vector } \\
\text { Machine Radial } \\
\text { (SVMR) }\end{array}$ & $\begin{array}{l}\text { Delegated } \\
\text { Regressor Method } \\
\text { (DRM) }\end{array}$ \\
\hline 1 & 2505.088 & 6108.028 & 4826.279 & 1809.784 \\
\hline 2 & 2473.006 & 6149.988 & 4977.869 & 1806 \\
\hline 3 & 2416.071 & 6225.425 & 5318.782 & 2017.899 \\
\hline 4 & 2518.619 & 6365.508 & 6527.553 & 1927.861 \\
\hline 5 & 2593.956 & 6531.951 & 6699.957 & 1731.9 \\
\hline 6 & 2670.358 & 6745.238 & 7109.096 & 2479.699 \\
\hline 7 & 2761.739 & 6945.34 & 7704.349 & 2200.264 \\
\hline 8 & 3033.962 & 7150.594 & 9223.404 & 1991.526 \\
\hline 9 & 3135.076 & 7223.843 & 9424.501 & 2269.731 \\
\hline 10 & 3138.239 & 7396.725 & 9659.676 & 2291.885 \\
\hline 11 & 3596.169 & 7568.502 & 10229.27 & 2300.619 \\
\hline 12 & 3757.667 & 7618.878 & 10881.65 & 2667.437 \\
\hline
\end{tabular}

Table 1. Root mean squared error (RMSE) of different regression methods for prediction of radon concentration in soil with respect to different window sizes.

Support vector machine (linear and polynomial). Vladimir Vapnik, 1979 and his co-workers introduced a Support Vector Machines (SVMs) ${ }^{54}$. SVMs is a well-known method used for classification and regression problems both for linear and non-linear types of data ${ }^{39}$. By utilizing non-linear methods it refurbishes the data in to high dimensions. The main theme of support vector machines is to find the finest linear decision boundary to discriminate different categories. Moreover, the fastest version of SVMs can take much time for training of data but in result, returns the more accurate classifications or prediction. SVMs had been successfully applied for different regression problems $\mathrm{s}^{5-57}$ by maintaining the entire main features i.e. maximal margin that makes algorithm ability to differentiate itself. Support Vector Regression encompasses the same foundations as we used as the SVMs for classification tasks only having a few little differences. As we know that in regression problems, the output is the real values that make it difficult to predict the information at hand because of having inestimable possibilities. In order to make it predictable, epsilon (margin of tolerance) is approximated to the SVM that is previously asked from the problem. On the other hand, in order to minimize the error rate, hyperplane are individualized based on how much they maximize the margin and also taking in to account that part of error is tolerated.

As like SVM works for classification problems, regression is also done by providing a loss function that tolerates errors within a certain margin ${ }^{58}$. Moreover, that $\varepsilon$-band contain points called as support vectors ${ }^{59}$.

$$
L(y, f(x, w))=\left\{\begin{array}{l}
0 \quad \text { if }|y-f(x, w)|<\varepsilon \\
|y-f(x, w)|-\varepsilon, \text { otherwise }
\end{array}\right.
$$

where $f(x, w)$ is a linear model function;

$$
f(x, w)=\sum_{j=1}^{m} w_{j} g_{j}(x)+b
$$

with $g_{j}(x)$ as a set of transformation functions that are aimed to map input $\mathrm{x}$ to $\mathrm{m}$-dimensional feature space. $\mathrm{b}$ is the bias term, which can be ignored when the data is preprocessed to be zero-mean. Basic representations of SVM and SVR with slacked variables are shown inFigs. 2 and 3 respectively ${ }^{60,61}$.

\section{Results and Discussion}

This section presents the results to evaluate the performance of the proposed methodology, delegated regressor, in comparison with other regression methods in terms of different performance measure and accuracy for predicting radon concentration during the seismic periods of windows ranging for size 1 to 12 .

It is noted that upon increasing the window size, the error in prediction of the radon concentration increases. This is due to decrease in training data samples caused by splitting of data during each window operation. As the window size increases the radon seismic data samples grows at the cost of decreasing number of instances for training of MLs, as shown in Fig. 4.

Figure 4 shows the number of measurements after splitting of whole data in to seismic activity (SA) and non-seismic activity (NSA) datasets. Non-seismic data set are those days for which no seismic activity have been observed. And these non-seismic data sets dynamically change with respect to window size.

Figure 5 shows the mean linear correlation regarding different regression methods for the actual and predicted radon concentrations in soil. With the fact that number of measurements gets decreased with the increase in window size, the correlation between the actual and predicted radon concentration in soil also decreases. The best correlation found between the actual and predicted radon concentration is at window size of 2 . This demonstrates those two days before and after the seismic activities are very important in order to accurately predict the radon anomaly which is an earthquake precursor. 

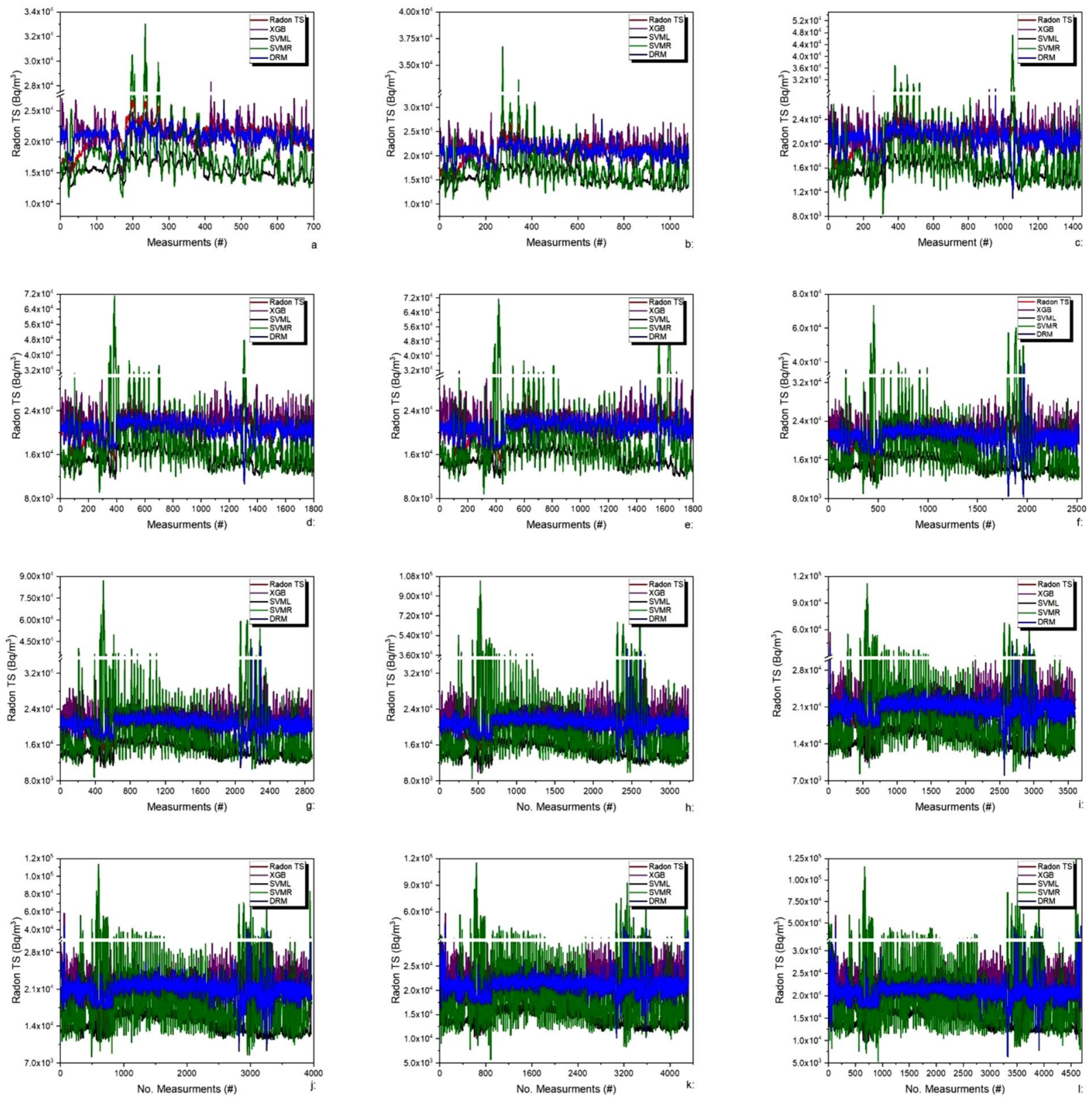

Figure 6. (a-l) Represents radon concentration for 1 through 12 days before and after earthquake with red lines actually showing the earthquake with its magnitude.

\section{Comparison of Delegated Regressor with Other Traditional Regressors}

Results obtained from proposed delegated regressor algorithm have been compared with other regression methods for the prediction of radon concentration in soil. The dataset distribution regarding SA and NSA was carried out in such a way that SA data contains varying number of days ranging from 1 to 12 before and after the seismic activity.

Table 1 presents the error rate of proposed delegated and other regression methods for the prediction of radon concentration in soil. On the same dataset, regarding same window size extracted data, the proposed delegated Regressor outperforms then other regression methods having minimum RMSE. Experimental data for the period from 05 February 2017 to 16 February 2018 is used for computer experimentations and simulation purpose.

The maximum error rate for the proposed methodology (2667.437) is appreciably smaller when compared to other Regressor methods (XGBoost, SVML and SVMR) having maximum error rates of 3757.667, 7618.878 and 10881.65 respectively.

For the window 1, one day before and after earthquake, Fig. 6(a) shows the actual and predicted RTS data using delegated and other regression methods. On the $\mathrm{X}$ axis we have a number of measurements and $\mathrm{Y}$ axis represents the radon concentration. The Fig. 6(a) shows that delegated Regressor predicts more accurately than other regression methods by overlapping real time RTS data with better results than other regression methods. Proposed delegated Regressor Method (PDRM) shows that RMSE is less for PDRM (1809.784) when compared to 

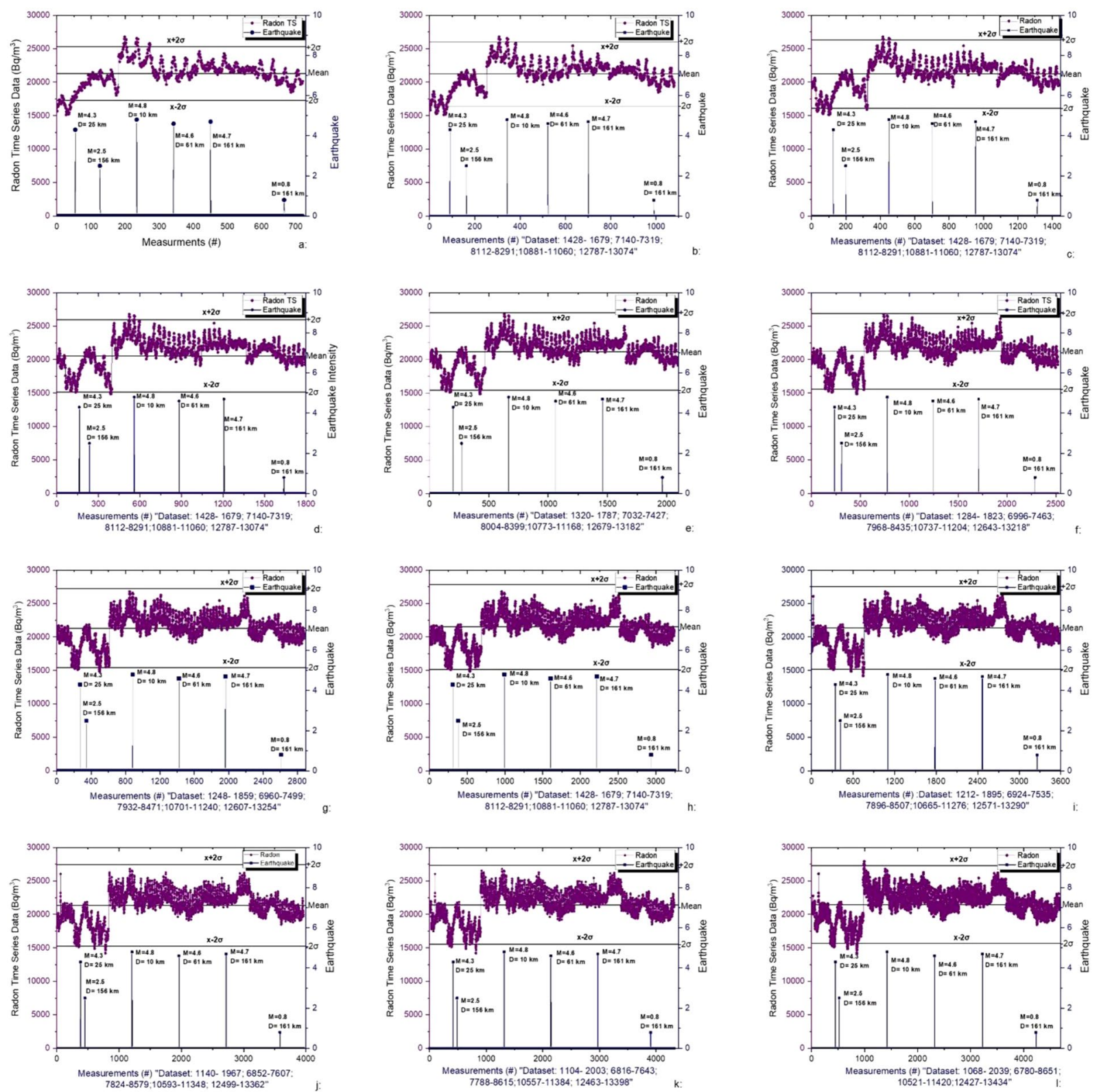

Figure 7. (a-l) Actual and predicted radon concentration using delegated and other regression methods using window size of one through 12 days.

other regression methods viz., XGBoost (2505.088), SVML (6108.028) and SVMR (4826.279) for the prediction of radon concentration in soil. All these evaluation criteria show that the PDRM outperforms other regression methods. Figure 6a shows anomalies in real RTS data can be predicted well by PDRM. Trend in series generated by PDRM follows trend of real RTS.

The results on same pattern were observed for the windows 2 through 12 . For the $2^{\text {nd }}$ window (see Fig. $6 \mathrm{~b}$ ), two (02) days before and after earthquake, we have obtained lowest value of RMSE as compared to all other windows. PDRM showed that RMSE is less for PDRM (1806) when compared to other regression methods viz., XGBoost (2473.006), SVML (6149.988) and SVMR (4977.869) for the prediction of radon concentration in soil.

RMSE computed from all MLs techniques and PDRM, for the window 3, shows that RMSE is less for PDRM (2017.899) when compared to other regression methods viz., XGBoost (2416.071), SVML (6225.425) and SVMR (5318.782) for the prediction of radon concentration in soil (see Fig. 6c). The results for all other windows 4 through 12 are shown in Table 1. All these statistics shows that the PDRM outperforms other regression methods for the window size 1 through 12. Almost for all windows, 1 through 12, PDRM trend follows RTS real time trend (see Fig. 6a-1).

Figure 7(a) through 7(l) shows the RTS data recorded from one through twelve days before and after each earthquake struck in the area of study. Vertical lines, olive green, show the earthquake with its magnitude (see Fig. $7 \mathrm{a}-1)$. 
Radon anomalies leading to possible earthquake have been predicted using the method of standard deviation (see Fig. 7a-1). To differentiate between anomalies caused by environmental data from seismic events we have chosen period for anomaly for which radon concentration is deviated by more than $\pm 2 \sigma^{61-64}$. For the window 1 four spikes, with radon concentration 26763, 26539, 25773 and $15127 \mathrm{~Bq} / \mathrm{m}^{3}$, in RTS data were recorded for which radon concentration deviated by more than $\pm 2 \sigma$. Anomaly, at $15127 \mathrm{~Bq} / \mathrm{m}^{3}$, in RTS data was followed by an earthquake, after one day, with magnitude 4.3 at the depth of $25 \mathrm{~km}$ with Lat $\left(34.91^{\circ} \mathrm{N}\right)$ and Long $\left(72.94^{\circ} \mathrm{E}\right)$ on $21^{\text {st }}$ of March 2017 (see Fig. 7a). Spike observed at $26763 \mathrm{~Bq} / \mathrm{m}^{3}$ was followed by another earthquake after one day with magnitude 4.8 at richter scale. Earthquake occurred at the depth of $10 \mathrm{~km}$ with Lat $\left(33.81^{\circ} \mathrm{N}\right)$ and Long $\left(73.19 \mathrm{E}^{\circ} \mathrm{E}\right)$ on $27^{\text {th }}$ of August 2017. Another spike in radon concentration $25773 \mathrm{~Bq} / \mathrm{m}^{3}$ was followed by earthquake of magnitude 4.6 after one day. This earthquake occurred on $23^{\text {rd }}$ of September 2017 at the depth of $61 \mathrm{~km}$ with Lat $\mathrm{N}(35.48 \mathrm{~N})$ and Long $\mathrm{E}(73.01 \mathrm{E})$. For the window one it was observed that the three earthquakes were struck soon after observing radon anomaly before one day.

For the window 2, RTS deviated $-2 \sigma$ pattern during measurement 1490 and 1497 with radon soil concentrations 15126 and $15197 \mathrm{~Bq} / \mathrm{m}^{3}$ respectively. These anomalies in radon concentrations were followed by an earthquake of magnitude 4.3 during measurement number 1510. Two more anomalies in RTS data were observed, exceeding $+2 \sigma$, during measurement numbers 7196 and 7231 , followed by earthquake of magnitude 4.8 on richter scale. Almost same pattern was observed for rest of windows 3 through 12.

\section{Conclusion}

This study proposed a new approach for regression based on delegating classifiers. The idea behind the proposed method is that the examples having predictions not lie on a reliable threshold gets delegated to the next lower level with the hope that the regressor at the next level will become more specialized to predict these delegated examples. Moreover, we have also compared the proposed delegated regressor to other machine learning methods such as XGBoost, SVML and SMR to predict radon concentration in soil gas from measured environmental data, i.e. relative humidity, temperature and pressure. From the statistics above we have concluded that the proposed methodology predicts the radon concentration with more precision for all the window sizes by overlapping the actual radon concentration and all of the 6 earthquakes. Our measurements are still in progress and further analyses will be carried out over longer number of measurements.

\section{Data availability}

All data included in the manuscript are available upon request by contacting with the corresponding author.

Received: 19 February 2019; Accepted: 27 January 2020;

Published online: 20 February 2020

\section{References}

1. Ulomov, V. I. \& Mavashev, B. Z. Precursor of a strong tectonic earthquake. Acad. Sci. USSR, Doklady, Earth Sci. Sec. 176, 9-11 (in Russian). (1967)

2. Sultankhodzhayev, A. N., Chernov, I. G. \& Zakirov, T. Hydroseismological premonitors of the Gazli earthquake. Proc. Uzb. SSR Acad. Sci. 7, 51-53 (in Russian). (1976)

3. Wakita, H. Geochemistry related to earthquake prediction in China. In: Proceedings on the Chinese Earthquake Prediction by the 1977 Delegation of the Seismological Society of Japan, 113-134 (in Japanese). (1978a)

4. Wakita, H. Earthquake prediction and geochemical studies in China. Chin. Geophys. (English Tranl.) 1(2), 443-457 (1978b).

5. Pulinets S. A. \& Boyarchuk, K. Ionospheric precursor of earthquakes. Springer, Berlin, Germany, 315 pp. ISBN 9783540208396 (2004).

6. Pulinets, S. A., Alekseev, V. A., Legen'ka, A. D. \& Khegai, V. V. Radon and metallic aerosols emanation before strong earthquakes and their role in atmosphere and ionosphere modification. Adv. Space Res. 20, 2173-2176 (1997).

7. Pulinets, S. A., Biagi, P., Tramutoli, V., Legen'ka, A. D. \& Depuev, V. Kh. Irpinia earthquake 23 November 1980: lesson from Nature revealed by joint data analysis. Ann. Geophys. 50, 61-78 (2007).

8. King, C. Y. Radon emanation on San Andreas Fault. Nature. 271, 516-519 (1978).

9. Mogro-Campero, A., Fleischer, R. L. \& Likes, R. S. Changes in subsurface radon concentration associated with earthquakes. Journal of Geophysical Research. 85, 3053-3057 (1980).

10. King, C. Y. Episodic radon changes in subsurface soil-gas along active faults and possible relation to earthquakes. J. Geophys. Res. 85, 3065-3078 (1980).

11. King, C. Y. Radon monitoring for earthquake prediction in China. Earthquake Prediction. Research. 3(1), 47-68 (1985).

12. King, C. Y. \& Minissale, A. Seasonal variability of soil-gas radon concentration in central California. Radiation Measurements. 23(4), 683-692 (1994).

13. King, C. Y. Radon, gas geochemistry, ground water and earthquakes. In: Katase, A., Shimo, M. (Eds.), Proceedings of the Seventh Tohwa University International Symposium on Radon and Thoron in Human Environment, 115-123 (1988).

14. Ramola, R. C., Singh, S. \& Virk, H. S. A model for the correlation between radon anomalies and magnitude of earthquakes. Nuclear Tracks and Radiation Measurements. 15(1-4), 689-692 (1988).

15. Ramola, R. C., Singh, M., Sandhu, A. S., Singh, S. \& Virk, H. S. The use of radon as an earthquake precursor. Nuclear Geophysics. 4(2), 275-287 (1990).

16. Ramola, R. C., Prasad, Y., Prasad, G., Kumar, S. \& Choubey, V. M. Soil-gas radon as seismotectonic indicator in Garhwal Himalaya. Applied Radiation and Isotopes. 66(10), 1523-1530 (2008).

17. Ramola, R. C. Relation between spring water radon anomalies and seismic activity in Garhwal Himalaya. Acta Geophysica. 58(5), 814-827 (2010).

18. Virk, H. S. \& Singh, B. Correlation of radon anomalies with earthquake in Kangra valley. Nucl. Geophys. 6, 293-300 (1992).

19. Vaupotic, J., Riggio, A., Santulin, M., Zmazek, B. \& Kobal, I. A radon anomaly in soil gas at Cazzaso, NE Italy,as a precursor of an ML $=5.1$ earthquake. Nukleonika. 55, 507-511 (2010).

20. Walia, V. et al. Earthquake prediction studies using Radon as a precursor in N-W Himalayas, India: a case study. Terrest., Atmosph. Ocean. Sci. 16, 775-804 (2005).

21. Virk, H. S. Radon monitoring of microseismicity in the Kangra and Chamba valley. Nucl. Geophys. 9, 141-146 (1995).

22. Virk, H. S., Sharma, A. K. \& Walia, V. Correlation of alpha logger radon data with microseismicity in N-W Himalaya. Curr. Sci. 72, 656-663 (1997). 
23. Ghosh, D., Deb, A. \& Sengupta, R. Anomalous radon emission as precursor of earthquake. Journal of Applied Geophysics. 69(2), 67-81 (2009).

24. Yang, T. F. et al. Variation of soil radon and thoron concentrations in a fault zone and prospective earthquakes in S-W Taiwan. Radiat. Meas. 40, 496-502 (2005).

25. Stranden, E., Kolstad, A. K. \& Lind, B. Radon exhalation-moisture and temperature dependence. Health Physics. 47(3), 480-484 (1984). 26. Friedmann, H. Radon in earthquake prediction research. Radiat. Prot. Dosim. 149, 177-184 (2012).

27. Imme, G. \& Morelli D. Radon as earthquake precursor, earthquake research and analysis - statistical studies, observations and planning. In: D’Amico S. (ed), InTech Europe, Rijeka, Croatia, 470 pp., https://doi.org/10.5772/2461 (2012).

28. Dmeroski, S. Applications of KDD methods in environmental sciences. In: Kloesgen, W., Zytkow, J. (Eds.), Handbook of Data Mining and Knowledge Discovery. Oxford University Press, Oxford (2002).

29. Negarestani, A., Setayeshi, S., Ghannadi-Maragheh, M. \& Akashe, B. Layered neural networks based analysis of radon concentration and environmental parameters in earthquake prediction. Journal of environmental radioactivity 62, 225-233 (2002).

30. Negarestani, A., Setayeshi, S., Ghannadi-Maragheh, M. \& Akashe, B. Estimation of the radon concentration in soil related to the environmental parameters by a modified Adaline neural network. Applied Radiation and Isotopes. 58(2), 269-273 (2003).

31. Torkar, D., Zmazek, B., Vaupotic, J. \& Kobal, I. Application of artificial neural networks in simulating radon levels in soil gas. Chemical Geology. 270(1-4), 1-8 (2010).

32. Dzeroski, S., Todorovski, L., Zmazek, B., Vaupotic, J. \& Kobal, I. Modelling soil radon concentration for earthquake prediction. Discovery Science, Proceedings. 2843, 87-99 (2003).

33. Sikder, I. U. \& Munakata, T. Application of rough set and decision tree for characterization of premonitory factors of low seismic activity. Expert Systems with Applications. 36(1), 102-110 (2009).

34. Zmazek, B., Todorovski, L., Dzeroski, S., Vaupotic, J. \& Kobal, I. Application of decision trees to the analysis of soil radon data for earthquake prediction. Applied Radiation and Isotopes. 58(6), 697-706 (2003).

35. Zmazek, B. et al. Radon in a thermal spring: Identification of anomalies related to seismic activity. Applied Radiation and Isotopes. 64(6), 725-734 (2006).

36. Steinitz, G., Begin, Z. B. \& Gazit-Yaari, N. Statistically significant relation between radon flux and weak earthquakes in the Dead Sea rift valley. Geology. 31(6), 505-508 (2003).

37. Park, C. H. \& Park, H. A relationship between LDA and the generalized minimum squared error solution. Journal on Matrix Analysis and Applications 27, 474-492 (2005).

38. Cover, T. M. \& Hart, P. E. Nearest neighbor pattern classification. IEEE Trans. Inform. Theory IT-13, 21-27 (1967).

39. Vapnik, V. N. Introduction to Statistical Learning Theory. IEEE transactions on neural networks 10, 988-999 (1979).

40. Breiman, L. Random forests. Machine learning 45, 5-32 (2001).

41. Ferri, C., Flach, P. \& Hernandez-Orallo, J. In Proceedings of the twenty-first international conference on Machine learning. 37 (ACM). ICML '04 Proceedings of the twenty-first international conference on Machine learning Banff, Alberta, Canada - July 04-08, (2004).

42. Man, M. Z. et al. Evaluating Methods for Classifying Expression Data. Journal of Biopharmaceutical Statistics 14, 1065-1084 (2004).

43. Nadeem, M. S. A., Zucker, J.-D. \& Hanczar, B. Proceedings of the third International Workshop on Machine Learning in Systems Biology, PMLR 8, 65-81 (2009).

44. Asim, K., Martínez-Álvarez, F., Basit, A. \& Iqbal, T. Earthquake magnitude prediction in Hindukush region using machine learning techniques. Natural Hazards 85, 471-486 (2017).

45. Asim, K. M., Idris, A., Iqbal, T. \& Martínez-Álvarez, F. Earthquake prediction model using support vector regressor and hybrid neural networks. PloS one. 13(7),e0199004 (2018 Jul 5).

46. Samui, P. \& Sitharam, T. Machine learning modelling for predicting soil liquefaction susceptibility. Natural Hazards and Earth System Sciences 11, 1-9 (2011).

47. Singh, M., Kumar, M., Jain, R. K. \& Chatrath, R. P. Radon in ground water related to seismic events. Radiation Measurements. 30(4), 465-469 (1999).

48. Freund, Y. \& Schapire, R. E. A Decision-Theoretic Generalization of On-Line Learning and an Application to Boosting. Journal of Computer and System Sciences 55, 119-139 (1997).

49. Ferri, C. \& Flach, P., J.H.-O. Delegating classifiers. In Proceedings of the twenty-first international conference on Machine learning ACM, 37 (2004).

50. Nielsen, D. T. B. With XGBoost-Why Does XGBoost Win" Every" Machine Learning Competition, NTNU (2016).

51. Guelman, L. Gradient boosting trees for auto insurance loss cost modeling and prediction. Expert Systems with Applications. 39, 3659-3667 (2012).

52. Friedman, J. H. Greedy function approximation: a gradient boosting machine. The Annals of statistics 29(5), 1189-1232 (2001).

53. Chen, T. \& Guestrin, C. In Proceedings of the 22nd ACM SIGKDD International conference on knowledge discovery and data mining. 22(4), 785-794 (2007).

54. Kouroupetroglou, P.-N. Machine Learning Techniques for Short-Term Electric Load Forecasting. Master Thesis, Aristotle University of Thessaloniki, Faculty of Sciences School of Informatics Department of Computer Science Knowledge, data and software technologies, UID 629 (2017).

55. Gunn, S. R. Support vector machines for classification and regression. ISIS technical report. 14, 5-16 (1998).

56. Jordaan, E. M. \& Smits, G. F. In IEEE International Joint Conference on Neural Networks. Budapest, Hungary, 2017-2022 (2004).

57. Sanchez, A. S., Nieto, P. G., Fernandez, P. R., del Coz Diaz, J. \& Iglesias-Rodriguez, F. J. Application of an SVM-based regression model to the air quality study at local scale in the Aviles urban area (Spain). Mathematical and Computer Modeling. 54, 1453-1466 (2011).

58. Heinermann, J. \& Kramer, O. In International Conference on Artificial Neural Networks. 797-804 (Springer) Heidelberg, (2014).

59. Burges, C. J. A tutorial on support vector machines for pattern recognition. Data mining and knowledge discovery. 2, 121-167 (1998).

60. De Kruif, B. J. \& De Vries, T. J. In Advanced Intelligent Mechatronics, 2001. Proceedings. 2001 IEEE/ASME International Conference on. 272-277 (IEEE). (2001)

61. http://www.saedsayad.com/SVR_2.htm.

62. Ghosh, D., Deb, A., Sengupta, R., Patra, K. K. \& Bera, S. Pronounced soil-radon anomaly - Precursor of recent earthquakes in India. Radiation Measurements. 42(3), 466-471 (2007).

63. Gregoric, A., Zmazek, B. \& Vaupotic, J. Radon concentration in thermal water as an indicator of seismic activity. Collegium Antropologicum. 32, 95-98 (2008).

64. Tareen, A. D. K. et al. Automated anomalous behaviour detection in soil radon gas prior to earthquakes using computational intelligence techniques. Journal of environmental radioactivity 203, 48-54 (2019).

\section{Acknowledgements}

One of the authors M.R. is thankful to higher education commission of Pakistan for granting funds against Project No: 6453/AJK/NRPU/R\&D/HEC/2016. This work was funded in part by the Department of Energy National Nuclear Security Administration Consortium for Verification Technology award number DE-NA0002534 and

Department of Energy National Nuclear Security Administration Consortium for Monitoring, Technology, and Verification award number DE-FOA-0001875. M.R and K.J.K are thankful of all funding agencies. 


\section{Author contributions}

This research article is a part of PhD thesis work carried out by Mr. Aleem Dad Khan Tareen (ADKT) under the supervision of Prof. Dr. Muhammad Rafique. A.D.K.T. have installed the equipment and collected the data. M.R., A.A. Mir, A.D.K.T. and Prof. K.J.K. were involved in framing the idea of the study. K.J.K. assisted through technical guidance on the subject and contributed in writing of manuscript along with M.R. A.A. Mir, M.R. and A.D.K.T. were involved in computer programming and simulating the results. Kh.M.A. and M.S.A.N. remained involved in analyzing the results and technical discussion on the subject. Overall supervision and writing of the manuscript was carried by Prof. Dr. Muhammad Rafique.

\section{Competing interests}

The authors declare no competing interests.

\section{Additional information}

Correspondence and requests for materials should be addressed to M.R.

Reprints and permissions information is available at www.nature.com/reprints.

Publisher's note Springer Nature remains neutral with regard to jurisdictional claims in published maps and institutional affiliations.

(c) (i) Open Access This article is licensed under a Creative Commons Attribution 4.0 International License, which permits use, sharing, adaptation, distribution and reproduction in any medium or format, as long as you give appropriate credit to the original author(s) and the source, provide a link to the Creative Commons license, and indicate if changes were made. The images or other third party material in this article are included in the article's Creative Commons license, unless indicated otherwise in a credit line to the material. If material is not included in the article's Creative Commons license and your intended use is not permitted by statutory regulation or exceeds the permitted use, you will need to obtain permission directly from the copyright holder. To view a copy of this license, visit http://creativecommons.org/licenses/by/4.0/.

(c) The Author(s) 2020 